\title{
A set of color-graphics routines for studying perceptual learning on the IBM PC
}

\author{
WILLIAM MARKS and JAMES B. GREER \\ Memphis State University, Memphis, Tennessee
}

\begin{abstract}
We describe a set of color-graphics routines that permit implementing perceptual learning studies on IBM PCs. Stimulus items may be presented in $320 \times 200$ graphics mode, using 4 colors from a 16-color palette. There are 256 levels of stimulus clarification that may be either subject-paced, in which case the subject makes keypresses until the stimulus can be identified, or program-paced. The perceptual learning task may involve either mask clarification or dot clarification. A description of the present level of development of the procedures, and of several demonstration experiments, is presented.
\end{abstract}

A number of studies have shown that there are dissociations between direct and indirect measures of retention (e.g., Graf \& Schacter, 1985; Jacoby \& Dallas, 1981). Direct measures of retention involve memory tasks (e.g., free recall and recognition) that require subjects to consciously remember previously learned stimulus events. Indirect measures of retention are tasks that do not require conscious recollection, but that indirectly reveal retention for previous material when performance on a perceptual learning task is facilitated by previous exposure to the material. Numerous studies have shown that manipulations of encoding variables that affect memory performance in direct measures of retention have no effect on indirect measures of retention (e.g., Carroll, Byrne, \& Kirsner, 1985; Jacoby \& Dallas, 1981; Mitchell \& Brown, 1988; Weldon \& Roediger, 1987). Indirect measures of retention include completion of word or picture fragments (e.g., see Graf, Mandler, \& Haden, 1982; Roediger \& Blaxton, 1987; Weldon \& Roediger, 1987) and perceptual identification of pictures or words (e.g., see Carroll et al., 1985; Jacoby \& Brooks, 1984; Warren \& Morton, 1982). The typical finding is that there are repetition priming effects in which prior exposure to test materials facilitates performance on the perceptual learning task independently of performance on direct measures of retention. Indirect measures of retention have also been extensively used in neuropsychological studies to investigate memory functioning in clinical populations (e.g., Warrington, 1982), as well as in developmental studies of childrens' perceptual learning (e.g., Carroll et al., 1985; Gollin, 1960).

\footnotetext{
The research reported in this paper was supported by funding to the Department of Psychology and the Center for Applied Psychological Research at Memphis State University, through the Centers of Excellence Program of the State of Tennessee. The authors would like to thank Wendellyn Brown, Rhonda Clark, Karen McCune, Gwen Milner, Richard Roberts, and Toni Whitaker for their assistance. Address correspondence to William Marks, Department of Psychology, Memphis State University, Memphis, TN 38152.
}

Several procedures have recently been developed for implementing perceptual learning studies with the Apple family of computers. Vokey, Baker, Hayman, and Jacoby (1986) have developed several assembly language programs that permit degraded pictures, as well as other stimuli, to be enhanced by either mask clarification or dot clarification programs on the Apple II. Brooks (1987) has provided a similar set of procedures for conducting perceptual identification experiments with tasks that can be implemented on the Apple Macintosh. Snodgrass, Smith, Feenan, and Corwin (1987) have developed another set of procedures that creates fragmented pictures on the Macintosh.

This paper reports a set of color-graphics procedures that we have developed for implementing perceptual identification tasks on the IBM AT, XT, PC, and fully compatible clones. The programs we describe allow the experimenter to present sequences of pictures or words on the screen for some specified duration and to control the interval between successive items. Degraded images of the stimulus items may then be presented along with new items in a perceptual learning task. The experimenter has the option of clarifying items by selecting a dot clarification or mask clarification routine (Vokey et al., 1986). The clarification of items may be either subject-paced, with the subject making keypresses to clarify the picture, or program-paced. The unique features of the present procedures are the ability to implement perceptual identification studies using the PC-DOS family of computers, and the ability to utilize color-graphics in perceptual identification studies.

\section{PROGRAM DESCRIPTION}

The program consists of a set of $C$ routines developed using Borland's Turbo C programming package. Although most of the code may be transported, certain portions of the routines include specific features of color-graphics adapters used in IBM PC, XT, and AT machines, and fully compatible clones. In particular, the graphics image 
degradation functions currently support only the medium resolution color graphics mode (mode 4) on machines with color-graphics adapters. The degradation functions essentially duplicate those provided by Vokey et al. (1986) for the Apple II family of computers, with the added dimension of color. The mask and dot clarification algorithms make use of a random mask image that is compared to the original image to produce a noise-degraded image. The two clarification routines work principally the same. Both operate on images as byte streams of data. A clarification cycle consists of comparing an image byte to a random byte from a uniformly distributed image mask. Depending on which byte has the greatest binary value, one is sent to the screen. Since bytes are the lowest common denominator of comparison, there are 256 possible levels of clarification. The increment between presentation frames may be adjusted to any value between 1 and 256 . The image quality is improved with each keypress in the subject-paced mode, or within a certain time interval in the program-paced mode, until the subject can make an identification response. The amount of time taken to update an image from one "frame" to the next depends on the image and the computer, as do most graphics update procedures. In general, AT class machines are preferable, because the image update times are faster. Several program-paced images were randomly selected and image update time for full clarification of each image was tested on an IBM AT and XT. Image update time on an AT takes about $187 \mathrm{msec}$-approximately $48 \mathrm{sec}$ for a full clarification-and the update time on an XT takes about $277 \mathrm{msec}$-approximately $71 \mathrm{sec}$ for a full clarification. The update time is frequently given as being $16.63 \mathrm{msec}$ per pixel (Brooks, 1987). This time is the screen refresh rate for most systems. We could have developed the procedures to update the screen with one pixel per level of clarification; however, we chose to develop routines in which each level of clarification would constitute a detectable difference in the amount of stimulus clarification. That is, $187 \mathrm{msec}$ per each level of clarification seems to represent a reasonable unit of description for the identification of stimulus events in our routines. The mean number of pixels that are clarified per clarification level update is approximately 250 .

The images are stored in a public-domain file format, the GX1 format, created by Brightbill-Roberts \& Company for their Show Partner program (Show Partner is a trademark of Brightbill-Roberts \& Company, Ltd; the software is bundled with Microsoft's Mouse). This method employs two compression file techniques to yield very small file sizes; typically, the $16 \mathrm{~K}$ images take up less than $1 \mathrm{~K}$ of storage on disk, for a compression ratio of at least 16:1.

The image files are specified in input data files. Files are arranged in groups, each with a unique name. Data files may contain an unlimited number of groups; furthermore, groups may contain an unlimited number of images. The number of images supported is limited only to the size of the available disk space. Groups may contain references to the same images. If the learning phase of the program is executed, the experimenter is prompted for a group name from which to pull the image file names for presentation. The program then randomly selects the file order of presentation. It is an easy modification to instruct the program to read group names as defaults specifying the type of study trial and test type-including stimulus durations and interstimulus intervals-for different groups of subjects.

If the experimenter chooses to use the program-paced mode of stimulus clarification, the program uses a modified version of Sheppard's (1987) timing routine. Reaction times may be recorded to the nearest millisecond. Alternatively, if the subject-paced mode of clarification is chosen, the number of keypresses taken to identify the image is recorded. In addition, the program can easily be set up to record the total time taken for a subject-paced clarification. The output data files for each trial contain the images presented in order of presentation and the method of clarification used (dot or mask).

A series of stages in the mask clarification and dot clarification of a football helmet are shown in Figures 1 and 2 , respectively. The stimuli in the demonstration experiments reported below were 40 digitized versions of the pictures from the Snodgrass and Vanderwart (1980) picture set, as developed by Brooks (1985) for the Macintosh. The pictures were converted to an IBM PC file format by using a graphics file conversion routine called The Graphics Link, which is avis ble from PC Quik-Art, 394 S. Milledge Avenue, Suite 200, Athens, GA 30606. The files were converted to the GX1 file format by using Show Partner's Capture program, a memory-resident routine for capturing screens and saving the captured images as Show Partner picture files. The Graphics Editor in Show Partner was then used to clean up the converted pictures and color them. The Show Partner software can display up to 16 different colors at one time; the present procedure, however, uses $320 \times 200,4$-color graphics mode resolution, due to limitations on screen update.

The present routines also permit the presentation of letter and word stimuli for perceptual identification. The Show Partner Graphics Editor may be used to generate letter and word stimuli, as well as other graphic images, and to select different colors for the generated stimuli.

\section{EXPERIMENTAL FORMAT}

\section{Study Trials}

The design of the procedures currently begins with the presentation of a set of colored pictures for study. Study items may be virtually any item that can be represented in a $320 \times 200$ graphics mode. There are system prompts at the beginning of the learning trials, so that the experimenter may specify the stimulus duration and interstimulus interval. The program also records and collects reaction times to presented items. Thus, the experimenter may require an observer to simply study presented stimuli prior to test, or the experimenter may decide to collect 

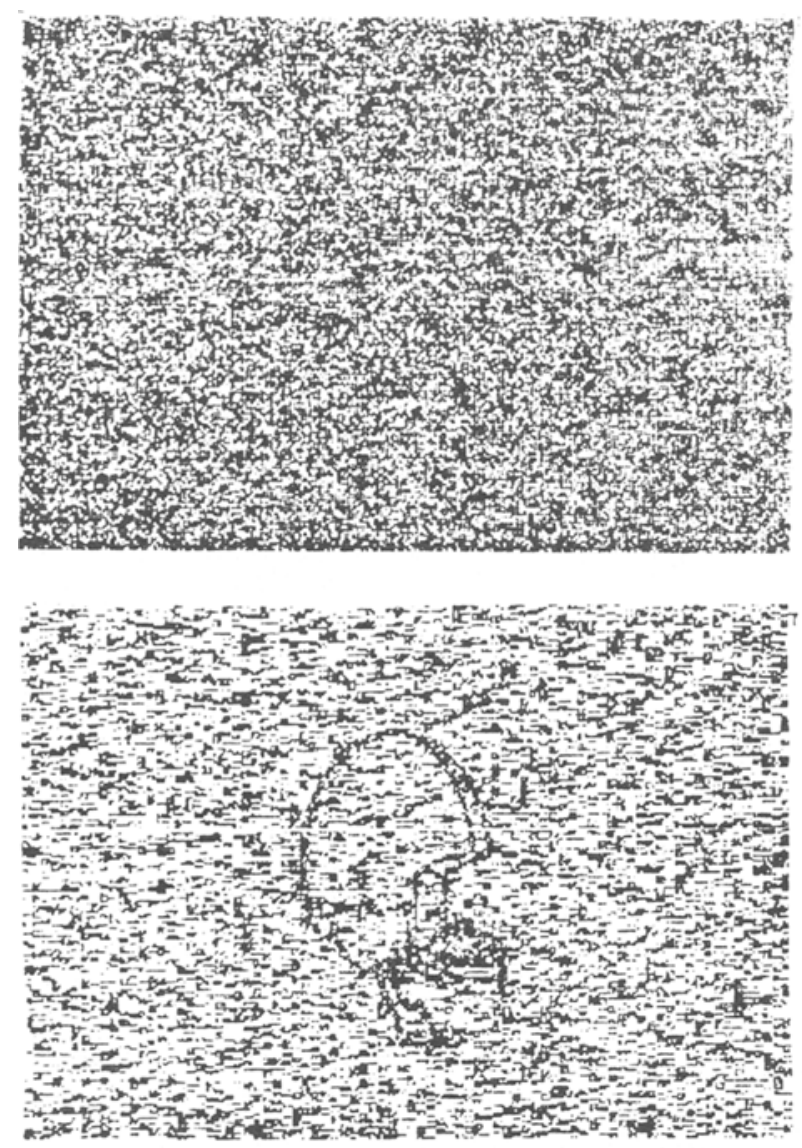
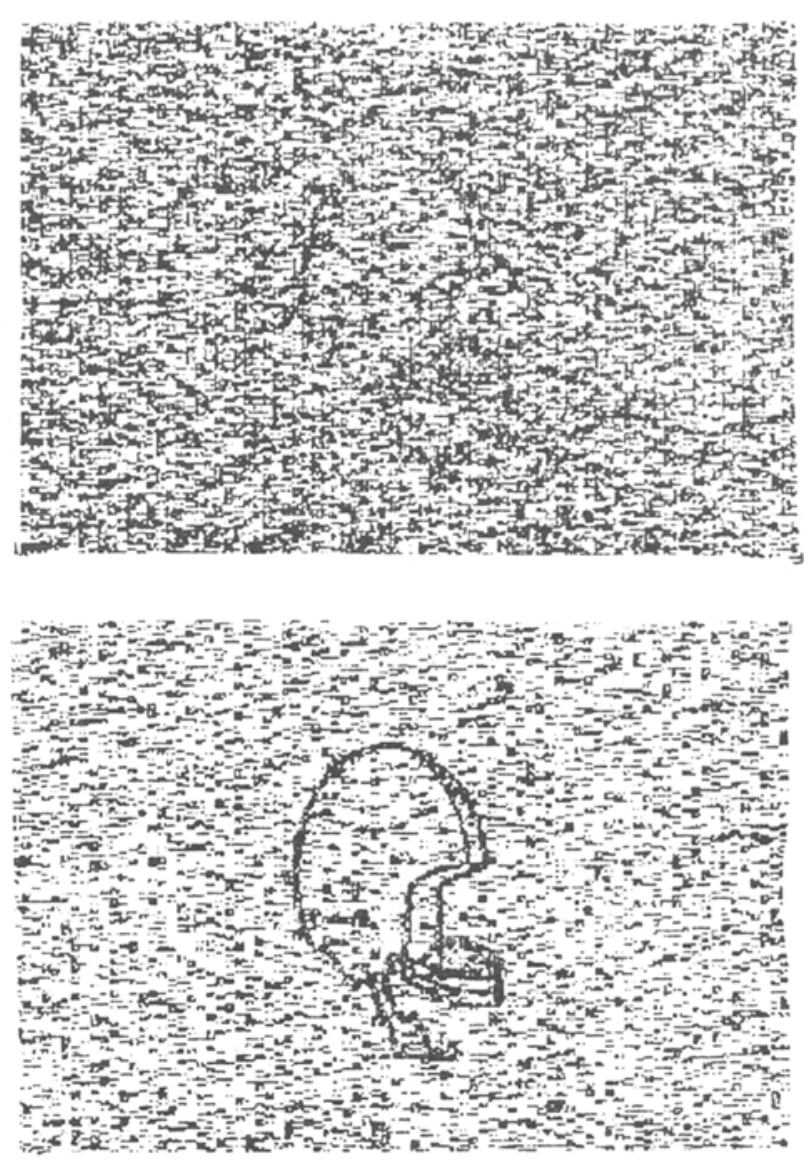

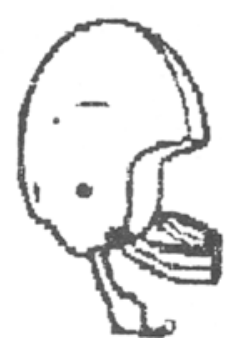

Figure 1. Example of sequence of steps in mask-clarifying a football helmet. The sequence shows $0 \%, 30 \%, 45 \%, 60 \%$, and $100 \%$ clarification.

reaction times to the presented stimuli in the context of encoding manipulations.

\section{Perceptual Identification Trials}

The perceptual identification trials may begin immediately following study, or following some delay, so that the experimenter can examine the effects of the retention interval on perceptual learning (e.g., see MacLeod, 1988; Mitchell \& Brown, 1988). The perceptual identification trials begin with a program prompt that asks the experimenter to select either mask clarification or dot clarification as the perceptual identification task, and to decide on either subject-paced or program-paced clarification. The program can easily be modified to permit the experimenter to select these options on a trial-by-trial basis.

Mask clarification. The mask clarification routine displays a colored picture that is completely occluded by a random noise mask with color pixels that are the same colors as those in the picture. The picture is slowly revealed until an identification response is made with the press of a key on the computer keyboard when the programpaced mode of mask clarification is selected. If the subjectpaced mode of stimulus clarification is selected, the subject clarifies the picture by pressing keys on the keyboard 

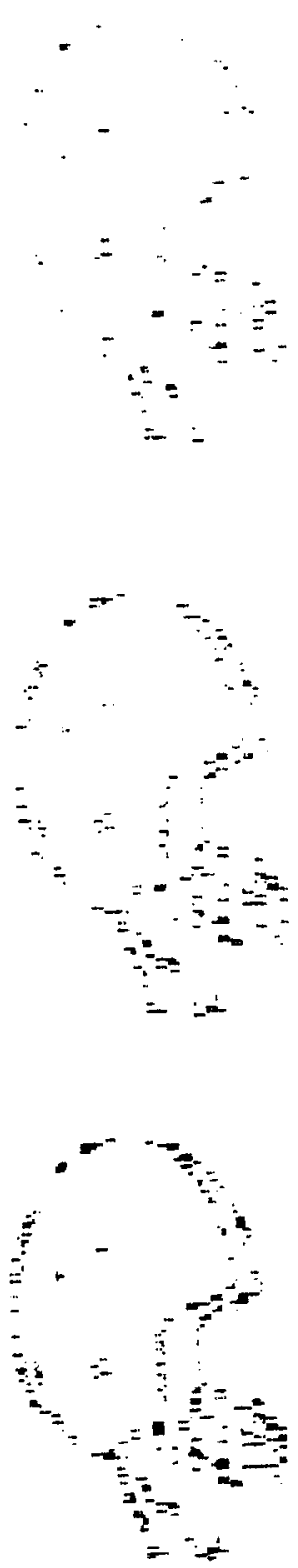

Figure 2. Example of sequence of steps in dot-clarifying a football helmet. The sequence shows 0\% (not shown here), 10\%, 20\%, $30 \%$, and $100 \%$ (not shown here; see Figure 1) clarification.

until the picture can be identified. The masks are randomly generated and clarified separately for each subject. Similar to other routines (Brooks, 1987; Vokey et al., 1986), dependent measures include number of keypresses to identify, and time to identify.

We now describe two demonstration experiments that were conducted to test the mask clarification procedure. In each experiment, subjects studied 20 pictures during learning by naming each picture as it was presented. The pictures were randomly presented on an IBM AT for $3 \mathrm{sec}$, with an interstimulus interval of $1.5 \mathrm{sec}$. The mask clarification task occurred immediately after learning. The clarification task consisted of 40 randomly presented pictures; half the pictures were previously seen during study, and the other half were new pictures.
We selected program-paced mask clarification in the first demonstration experiment. Twelve subjects were presented with the 20 pictures during learning and were then presented with the mask clarification task. As expected, there were large prior exposure effects on identification $[t(11)=5.85, p<.001]$. Mean time to identification was $14.85 \mathrm{sec}$ for old pictures, and $20.50 \mathrm{sec}$ for new pictures.

In the subject-paced mask clarification experiment, the same procedures were used, except that the dependent measure was number of keypresses to identify the pictures. There were again large prior exposure effects for previously seen pictures $[t(11)=4.22, p<.001]$. The mean numbers of keypresses were $\mathbf{7 4 . 9 8}$ for old pictures and 103.33 for new pictures.

Dot clarification. The dot clarification routine operates in a manner similar to Vokey et al.'s (1986) dot clarification procedure. The screen is initially blank until the subject presses a key or until a timing routine is called that begins revealing the picture. Each keypress or call to the timing routine reveals more of the picture as randomly chosen pixels are displayed.

Two experiments were conducted to test the dot clarification procedure. Except for changing the type of task, the design of the studies was identical to that of the two previous experiments. There were again large prior exposure effects for dot clarification in the program-paced mode $[t(11)=3.47, p<.001]$ and in the subject-paced mode $[t(11)=4.34, p<.001]$. The mean times for identification in the program-paced mode were $9.03 \mathrm{sec}$ for old pictures and $14.48 \mathrm{sec}$ for new pictures. The mean numbers of keypresses to identify the pictures in the subject-paced mode were $\mathbf{4 2 . 1 0}$ for old pictures and $\mathbf{6 5 . 1 9}$ for new pictures.

\section{AVAILABILITY}

Enhancements to the present routines are in progress. These enhancements include increasing the type of study trials that the routines will support, converting the entire set of the 260 Snodgrass and Vanderwart pictures to PC format, and generating same-name distractors for recognition and perceptual identification tasks. A disk containing the four demonstration experiments reported in this paper is available from the authors for $\$ 3$. The disk contains the 40 images used in the experiments, along with the executable files for running the experiments. A disk providing source code listings for the clarification routines and a disk of the demonstration experiments are available for $\$ 6$. Additional source code listings and program information may be had by contacting the authors.

\section{REFERENCES}

Brooks, J. O., III. (1985). Pictorial stimuli for the Apple Macintosh computer. Behavior Research Methods, Instruments, \& Computers, 17, 409-410.

Brooks, J. O., III. (1987). Enhancing and degrading visual stimuli. Behavior Research Methods, Instruments, \& Computers, 19, 260-269. Carroll, M., Byrne, B., \& Kirsner, K. (1985). Autobiographical 
memory and perceptual learning: A developmental study using picture recognition, naming latency, and perceptual identification. Memory \& Cognition, 13, 273-279.

Gollin, E. S. (1960). Developmental studies of visual recognition of incomplete objects. Perceptual \& Motor Skills, 11, 289-298.

Graf, P., Mandler, G., \& Haden, P. E. (1982). Simulating amnesic symptoms in normals. Science, 218, 1243-1244.

Graf, P., \& Schacter, D. L. (1985). Implicit and explicit memory for new associations in normal and amnesic subjects. Joumal of Experimental Psychology: Leaming, Memory, \& Cognition, 11, 501-518.

JACOBY, L. L., B BROKS, L. R. (1984). Nonanalytic cognition: Memory, perception, and concept learning. In G. H. Bower (Ed.), The psychology of learning and motivation (Vol. 18, pp. 1-47). New York: Academic Press.

JACOBY, L. L., DALLAS, M. (1981). On the relationship between autobiographical memory and perceptual learning. Journal of Experimental Psychology: General, 3, 306-340.

MACLEOD, C. M. (1988). Forgotten but not gone: Savings for pictures and words in long-term memory. Joumal of Experimental Psychology: Learning, Memory, \& Cognition, 14, 195-212.

Mitchell, D. B., \& Brown, A. S. (1988). Persistent repetition priming in picture naming and its dissociation from recognition memory. Journal of Experimental Psychology: Learning, Memory, \& Cognition, 14, 213-222.

Roediger, H. L., III, \& Blaxton, T. A. (1987). Effects of varying modality, surface features, and retention interval on priming in wordfragment completion. Memory \& Cognition, 15, 379-388.
SHEPPARD, B. (1987). High performance software analysis on the IBM PC. Byte, 12, 157-164.

Snodgrass, J. G., Smith, B., Feenan, K., \& Corwin, J. (1987). Fragmenting pictures on the Apple Macintosh computer for experimental and clinical applications. Behavior Research Methods, Instruments, \& Computers, 19, 270-274.

Snodgrass, J. G., VANDERWart, M. (1980). A standardized set of 260 pictures: Norms for naming agreement, familiarity, and visual complexity. Joumal of Experimental Psychology: Human Learning \& Memory, 6, 174-215

Vokey, J. R., Baker, J. G., Hayman, G., \& Jacoby, L. L. (1986). Perceptual identification of visually degraded stimuli. Behavior Research Methods, Instruments, \& Computers, 18, 1-9.

WARREN, C., MorTon, J. (1982). The effects of priming on picture recognition. British Journal of Psychology, 73, 117-129.

WARRINGTON, E. K. (1982). Neuropsychological studies of object identification. Philosophical Transactions of the Royal Society of London, 298B, 15-33.

WELDON, M. S., \& Roediger, H. L., III. (1987). Altering retrieval demands reverses the picture superiority effect. Memory \& Cognition, 15, 269-280.

(Manuscript received April 12, 1989; revision accepted for publication November $7,1989$. 